\title{
To Assess the Prevalence of Cognitive Impairment in Type II Diabetes Mellitus: An Observational Study
}

\author{
Shivani D. Godhasara ${ }^{1}$, Vaishali Suthar ${ }^{2}$ \\ ${ }^{1}$ Postgraduate Physiotherapy Student, Ahmedabad Institute of Medical Sciences (AIMS) Affiliated to Gujarat \\ University, Ahmedabad, Gujarat, India. \\ ${ }^{2}$ Assistant Professor, Ahmedabad Institute of Medical Sciences (AIMS) Affiliated to Gujarat University, \\ Ahmedabad, Gujarat, India.
}

Corresponding Author: Shivani Dipakbhai Godhasara

\begin{abstract}
Introduction: Diabetes mellitus is a chronic metabolic disease characterized by hyperglycemia that affects various body systems. Elevated blood glucose levels cause brain malfunction, sorbitol which damages blood vessels, and degeneration of the nerves that can lead to dementia or cognitive impairment. Cognitive impairment can result in nonadherence of patients to diabetes treatment, such as medication, diet and exercise.
\end{abstract}

Purpose: The purpose of this study was to assess the prevalence of cognitive impairment in type II diabetes mellitus.

Methodology: 50 participants of age group 30 - 60 years, both male and female were included in this study. Cognitive impairment was assessed with the English version of the Montreal Cognitive Assessment (MoCA) tool. The MoCA scoring according to Dementia and Driving Safety: A clinical guideline, Version 3, 2014.

Result: Among the 50 patients who were assessed, 24 (48\%) were cognitively impaired. 20 (40\%) of the subjects were age group of 51-60 years, and males participants $11(22 \%)$ outnumbered females 9 $(18 \%)$. The majority of patients $(40 \%)$ had diabetes type II for $<2$ years.

Conclusion: There was strong correlation found between Type II DM and cognitive impairment.

Key Words: Prevalence, Cognitive impairment, Diabetes mellitus Type II, Montreal Cognitive assessment (MoCA)

\section{INTRODUCTION}

Diabetes mellitus is a chronic metabolic disease characterized by hyperglycemia that affects various systems of the body. For this progressive, and incurable condition, the best scenario after diagnosis is good metabolic control and risk factor management to forestall vascular and neuropathic complications. ${ }^{[1]}$ The prevalence of both type I and type II Diabetes mellitus is increasing worldwide, the prevalence of type II DM is much more rising rapidly, especially in developing countries like India and China because of increasing obesity, reduced activity levels and also because of the ageing of the population. ${ }^{[2]}$ People with diabetes often develop diverse microvascular, macrovascular and neuropathic complications that affects the quality of life. ${ }^{[3]}$ Diabetes mellitus (DM) is a worldwide major pathological condition due to its high prevalence, negative impact on lifespan and quality of life, as well as the extremely high costs requires. ${ }^{[4]}$ Worldwide increasing population and increasing sedentary lifestyle have led to rise in diabetes, with a $72 \%$ increase in disease projected by $2030 .^{[5]}$ 
Diabetes type II is caused by a combination of resistance to insulin action and an inadequate compensatory insulin secretory response. ${ }^{[6]}$ The impaired insulin metabolism in diabetic patients results in widespread morbidities involving the renal, retinal, cardiovascular, and peripheral nervous systems ${ }^{[7]}$ and also affects cognition. ${ }^{[8]}$ Elevated blood glucose levels cause brain malfunction, promote the synthesis of sorbitol, which blood vessels damages and degeneration of the nerves. ${ }^{[9]}$ Oxidative stress, microvascular vasculopathy, inflammation, dyslipidemia, and microalbuminuria are other key mediators resulting in neuropathology that can lead to cognitive impairment or dementia. ${ }^{[10]}$

Patients are said to be cognitively impaired when they have difficulties in remembering, learning new things, concentrating, or making decisions that affects daily life. Cognitive impairment, especially for those people who chronic diseases, is likely to be an obstacle to providing appropriate medical treatment, as patient understand need of treatment, regular follow-up and self-care can be limited by the cognitive impairment. ${ }^{[11]}$ Cognitive impairment might result in nonadherence with medication, diet and exercises. ${ }^{[12]}$ Cognitive impairment has also increased the risk of major cardiovascular events and all-cause mortality. ${ }^{[13]}$

Studies about the relationship between cognitive impairments and diabetes mellitus are inconclusive because of inconsistent reports, in findings may be attributable to differences in study deign, study subjects, duration or severity of diabetes, and the tools used for assess cognitive impairments. ${ }^{[14]}$ Montreal Cognitive Assessment (MoCA), was developed to assess the mild cognitive impairments, but few studies have reported using the MoCA in community settings. ${ }^{[15]}$ A pilot study from Canada reported the MoCA appears to be a better screening tool than the Mini-Mental State Examination for detecting mild cognitive impairment in the diabetic population. ${ }^{[16]}$

Diabetes - related cognitive impairment seriously challenge the demand for future health resources because of the increasing prevalence of T2DM and prolonged life-span. Thus, the purpose of the study was to assess the prevalence of Cognitive Impairment in Type II Diabetes Mellitus. So that effective treatment plan can be done.

Aim of the study is to assess the severity of cognitive impairments in type II diabetes mellitus.

Objectives of the study was, (i) To assess the severity of duration in Type II DM. (ii) To assess the severity of cognitive impairments in Type II DM. (iii) To assess the severity of duration on cognitive impairments in Type II DM.

\section{MATERIALS AND METHOD}

Source of collection of data: After obtaining Institutional ethical committee clearance, 50 subjects (male and females) were selected for this study base on inclusion and exclusion criteria.

Study design: A cross-sectional study

Sampling method: Samples were taken by simple random sampling method

Materials used: Pen, paper, pencil, writing pad, MoCA tool

\section{INCLUSION CRITERIA}

- Subjects diagnosed with Type II DM > 3 months

- Age group of 30 - 60 years, both male and female

- According to American Diabetes Association (ADA) guidelines, Fasting Blood Sugar $\geq 126 \mathrm{mg} / \mathrm{dL}$ or HbA1c $\geq$ $6.5 \%$

- willing to participated

\section{EXCLUSION CRITERIA}

- Subjects who had Metabolic diseases (HTN, Thyroid), Neuro-psychological disorder, Systemic illness, any other chronic diseases and pregnant females. 
Sampling Procedure: Initial contact was made in the community and suitable subjects were identified. Consent formed was taken from those who were willing to participate in the study. The purpose of the study was explained to the participants, and they were informed that refusal to participate would not affect the ongoing treatment or outcome adversely.

Demographic details of the subjects were collected using socio-demographic and clinical data proforma designed especially for the study. Investigations like hemogram, random blood sugar, fasting blood sugar, postprandial blood sugar, and glycosylated hemoglobin, which were available, were recorded. The Cognitive impairment was assessed through the administration of the English Version of the MoCA. The MoCA assesses 7 cognitive domains: visuospatial/executive ( 5 points), naming (3 points), memory (5 points for delayed recall), attention (6 points), language (3 points), abstraction (2 points), and orientation (6 points); the upper score limit is 30 points. One point is added if the subject has $\leq 12$ years of education. The cutoff value is 26 . A score $\geq 26$ is considered normal. In this study scoring done according to Fisher, Mark, Thomson, Sue. (2014) Dementia and Driving Safety: A clinical guideline, Version 3. Where, the cutoff value is 27 . A score $>26$ is considered normal. A score between 18-26 is considered mild cognitive impairment. A score between 11-17 considered mild dementia. A score 6-10 considered moderate dementia. A score $<6$ considered severe dementia.

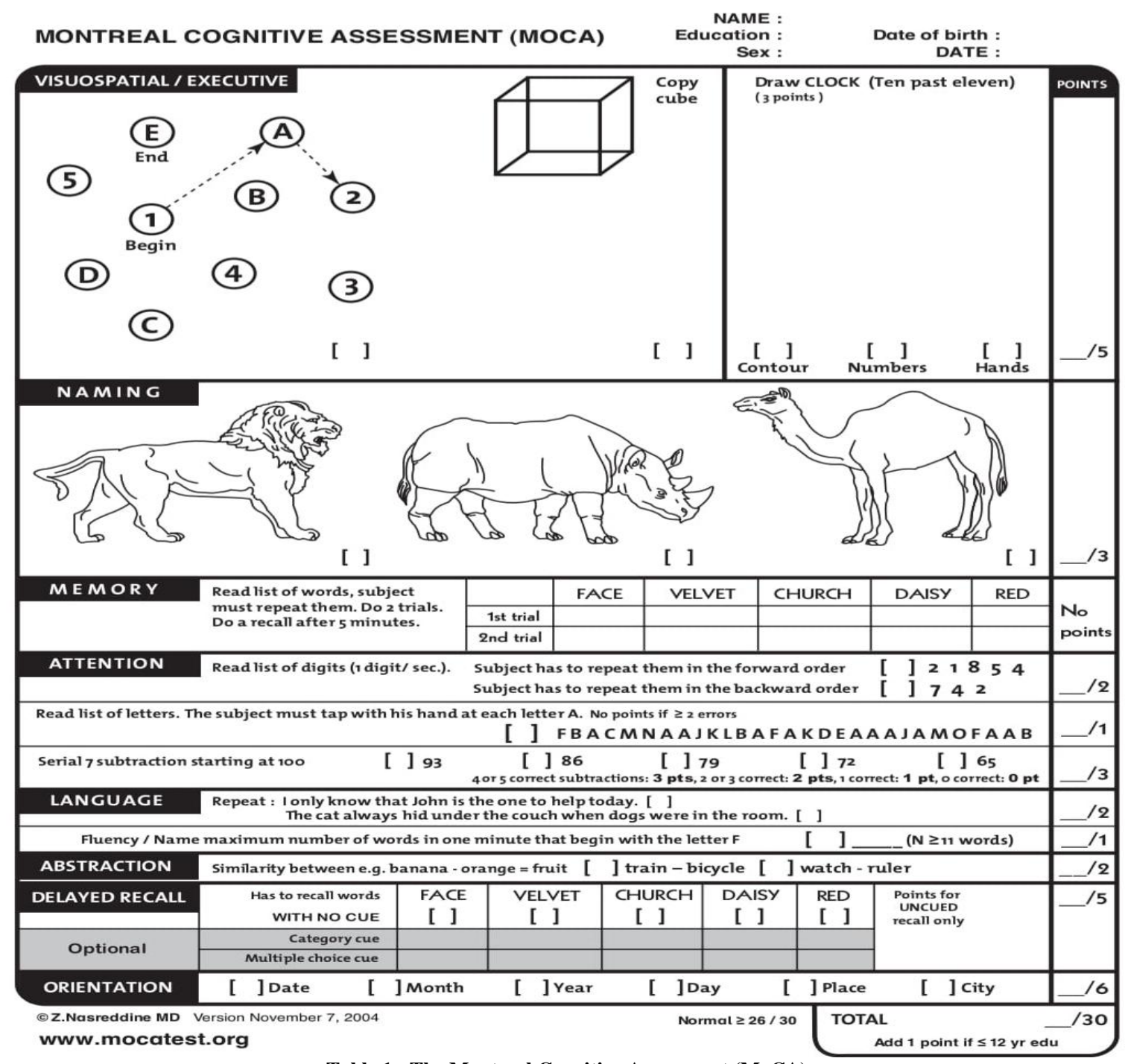

Table 1 : The Montreal Cognitive Assessment (MoCA) 
Shivani D. Godhasara et.al. To assess the prevalence of cognitive impairment in type II diabetes mellitus: an observational study.

\section{STATISTICAL ANALYSIS}

The data were analyzed for statistical significance by using the Microsoft Excel 2007.

\section{RESULT}

The study sample consisted of 50 participants with mean age $45.12 \pm 9.25$ years.
Among the 50 (26 males and 24 females) patients who were assessed, 24 (48\%) (10 males and 14 females) were cognitively impaired (score $<26$ on the MoCA) [Table 2]. The highest mean score was in the domain of attention 194 $(64.67 \%)$, while the lowest mean score was in the domain of naming $8(5.33 \%)$ [Figure $1]$.

Table 2: Demographic variables and their correlation with cognitive dysfunction

\begin{tabular}{|c|c|c|c|}
\hline Variable & $\begin{array}{l}\text { All Patients }(\mathrm{n}=50) \text {, } \\
\text { n }(\%)\end{array}$ & $\begin{array}{l}\text { Cognitive dysfunction Present }(n=24) \text {, } \\
n(\%)\end{array}$ & $\begin{array}{l}\text { Cognitive dysfunction Absent }(n=26), \\
n(\%)\end{array}$ \\
\hline Age (years) & & & \\
\hline $31-40$ & $18(36)$ & $6(25)$ & $12(46.15)$ \\
\hline $41-50$ & $12(24)$ & $6(25)$ & $6(23.08)$ \\
\hline $51-60$ & $20(40)$ & $12(50)$ & $8(30.77)$ \\
\hline Gender & & & \\
\hline Male & $26(52)$ & $10(41.67)$ & $16(61.54)$ \\
\hline Female & $24(48)$ & $14(58.33)$ & $10(38.46)$ \\
\hline Duration of Disease & & & \\
\hline$<2$ years & $20(40)$ & $6(25)$ & $14(53.85)$ \\
\hline $2-5$ years & $14(28)$ & $7(29.17)$ & $7(26.92)$ \\
\hline$>5$ years & $16(32)$ & $11(45.83)$ & $5(19.23)$ \\
\hline
\end{tabular}

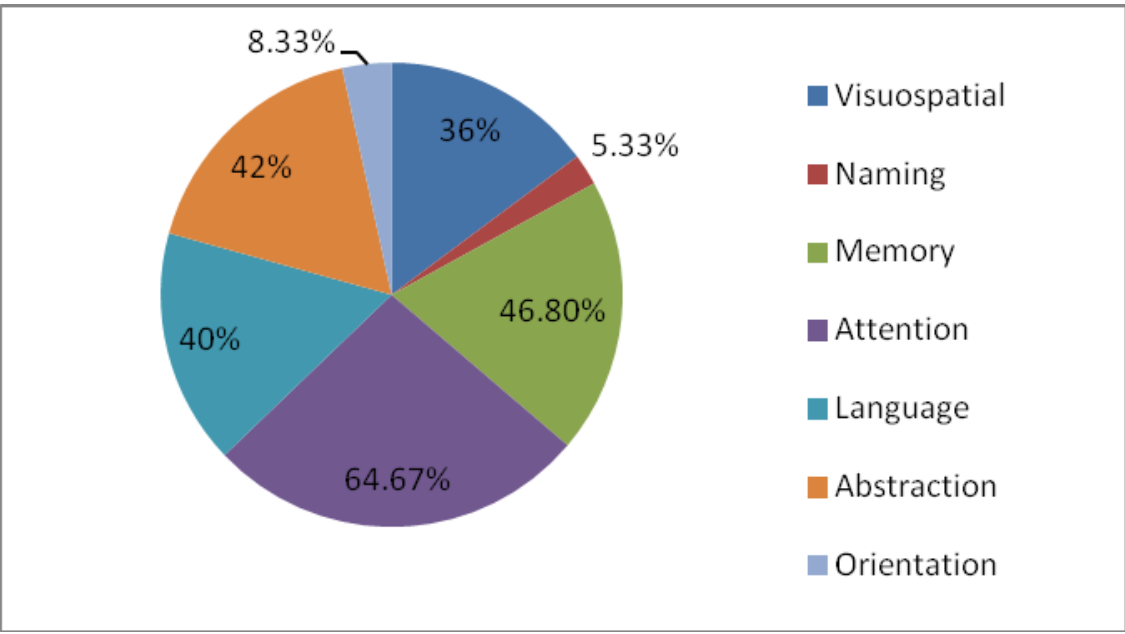

Figure 1 : Various types of cognitive impairments observed in \%

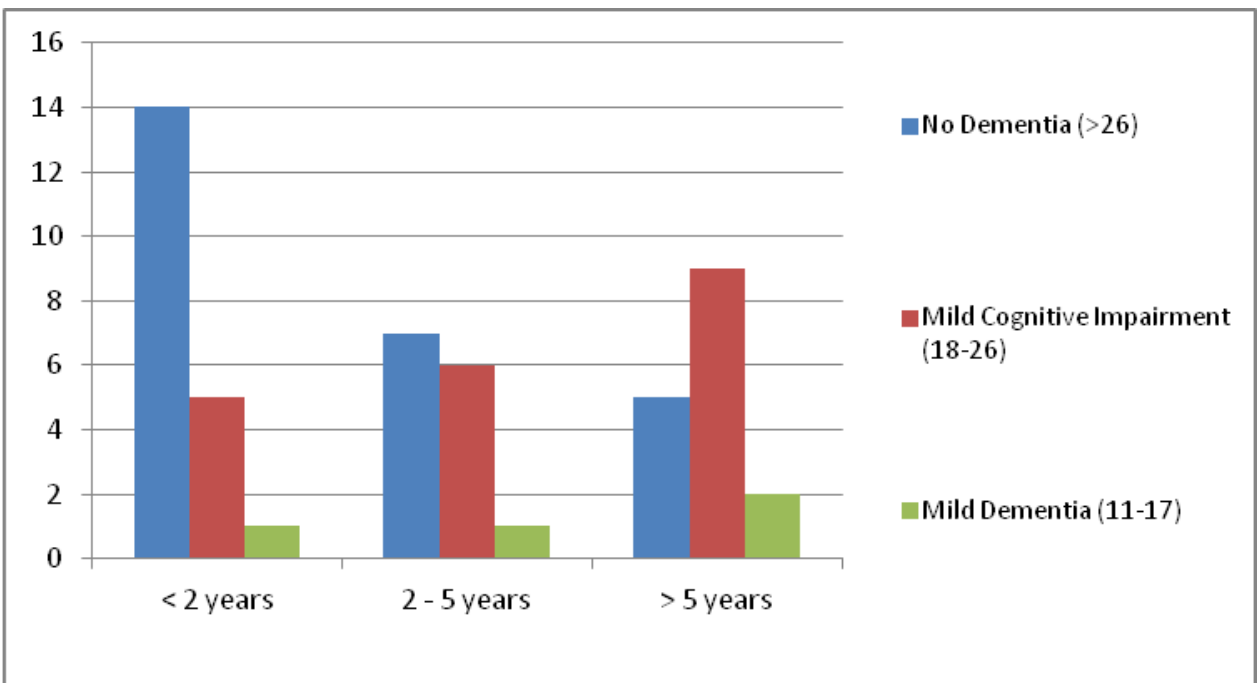

Figure 2 : correlation found between duration of T2DM and Cognitive impairments 
There was a correlation found between duration of T2DM and Cognitive impairments [Figure 2]. Participants with $<2$ years duration had no dementia $14(70 \%)$, mild cognitive impairment $5(25 \%)$ and mild dementia 1 (5\%). $2-5$ years duration had no dementia $7(50 \%)$, mild cognitive impairment $6(42.86 \%)$ and mild dementia 1 (7.14\%). >5 years duration had no dementia $5(31.25 \%)$, mild cognitive impairment $9(56.25 \%)$ and mild dementia 2 $(12.5 \%)$.

Among the participants, $20(40 \%)$ were 51-60 years of age, females 9 (45\%) and males $11(55 \%)$. At this age range maximum participants $12 \quad(60 \%)$ was cognitive impaired. Thus, there is an association of age with cognitive dysfunction.

Among those cognitive impaired a high proportion of females 14 (58.33\%) had cognitive dysfunction compared to males 10 $(41.67 \%)$ respectively.

\section{DISCUSSION}

T2DM is associated with accelerated cognitive decline ${ }^{[17]}$ and poor glycemic control is implicated in the development of cognitive dysfunctions. ${ }^{[18]}$

Cognitive domains that have been studied in T2DM include memory, psychomotor speed, visuospatial functions, frontal executive functions processing speed, verbal fluency attention and complex motor functions. ${ }^{[19]}$ The authors concluded that the most consistently reported measures were impairment in verbal memory and processing speed with preservation of functions including visuospatial function attention, semantic memory and language. [20] In the present study the domain, attention was highly affected among subjects, however, naming was least affected.

More than $55 \%$ of females had cognitive impairment in this study. This finding supported to the Salthouse study. ${ }^{[21]}$ Ferris et $\mathrm{al}^{[22]}$ showed cognitive decline to be more prevalent among females.
Ruis et $\mathrm{al}^{[17]}$ reported that modest cognitive decrements were identifiable at the early stage of T2DM. They also postulated hat diabetes duration seemed to be linked to the effect sizes of the studies. The longer duration of diabetes, the higher the noted effect size.

In our study, there was higher cognitive impairment in subjects with more than 5 years of T2DM.

Therefore, the study supports to assess the baseline prevalence is the first step in designing programs to address any health issue. Health education pertaining to cognitive decline, early identification, and management can be effective only when patients and caregivers are aware about importance of cognition and their treatment.

\section{CONCLUSION}

There was strong correlation found between Type II DM and cognitive impairment, which is highly prevalent. Evidences generated by varies studies suggest that cognitive dysfunction should be listed as one of the many complications of diabetes.

\section{Limitation Of Study}

This study was limited by its small sample size because of COVID 19 pandemic situation, and unequal distribution of participants.

\section{Future Study}

Further research can be carried out by larger sample size, on difference between rural and urban area and also include education, occupation, socio-economical status, and BMI.

\section{ACKNOWLEDGEMENT}

Special thanks to my ma'am who always supporting and guide me and also thanks all the participants that took part in this study and contributed to the study accomplishment.

\section{Conflict of Interest: None}




\section{Source of Funding: None}

\section{Ethical Approval: Approved}

\section{REFERENCES}

1. Yerrapragada DB, Rao CR, Karunakaran K, Lee HS. Cognitive dysfunction among adults with type 2 diabetes mellitus in Karnataka, India. Ochsner Journal. 2019 Sep 21;19(3):227-34.

2. Kataria L, Pandya H, Shah S, Shah H, Gerg R. Prevalence and pattern of cognitive dysfunction in type 2 diabetes mellitus. Int $\mathbf{J}$ Med Appl Sci. 2013;2(4):245-52.

3. Engelgau MM, Geiss LS, Saaddine JB, Boyle JP, Benjamin SM, Gregg EW, Tierney EF, Rios-Burrows N, Mokdad AH, Ford ES, Imperatore G. The evolving diabetes burden in the United States. Annals of internal medicine. 2004 Jun 1;140(11):945-50.

4. Albai O, Frandes M, Timar R, Roman D, Timar B. Risk factors for developing dementia in type 2 diabetes mellitus patients with mild cognitive impairment. Neuropsychiatric disease and treatment. 2019;15:167.

5. Kapoor D, Bhardwaj AK, Kumar D, Raina SK. Prevalence of diabetes mellitus and its risk factors among permanently settled tribal individuals in tribal and urban areas in northern state of sub-Himalayan region of India. International journal of chronic diseases. 2014 May 6;2014.

6. Mallorquí-Bagué N, Lozano-Madrid M, Toledo E, Corella D, Salas-Salvadó J, Cuenca-Royo A, Vioque J, Romaguera D, Martínez JA, Wärnberg J, López-Miranda J. Type 2 diabetes and cognitive impairment in an older population with overweight or obesity and metabolic syndrome: baseline cross-sectional analysis of the PREDIMEDplus study. Scientific reports. 2018 Oct 31;8(1):1-9.

7. Zimmet P, Alberti KG, Shaw J. Global and societal implications of the diabetes epidemic. Nature. 2001 Dec;414(6865):7827.

8. Luchsinger JA, Palmas W, Teresi JA, Silver S, Kong J, Eimicke JP, Weinstock RS, Shea $\mathrm{S}$. Improved diabetes control in the elderly delays global cognitive decline. The journal of nutrition, health \& aging. 2011 Jun;15(6):445-9.
9. Kodl CT, Seaquist ER. Cognitive dysfunction and diabetes mellitus. Endocrine reviews. 2008 Jun 1;29(4):494511.

10. Thakurta RG. A cross-sectional study of cognitive dysfunctions in type 2 diabetes mellitus. International Journal of Health and Clinical Research. 2021 Apr 29;4(8):265-8.

11. Banoo H, Nusrat N, Nasir N. Type 2 diabetes mellitus: a review of current trends. RAMA Univ J Med Sci. 2015; 1(2):50-57.

12. Martin LR, Williams SL, Haskard KB, DiMatteo MR. The challenge of patient adherence. Therapeutics and clinical risk management. 2005 Sep;1(3):189.

13. De Galan BE, Zoungas S, Chalmers J, Anderson C, Dufouil C, Pillai A, Cooper M, Grobbee DE, Hackett M, Hamet P, Heller SR. Cognitive function and risks of cardiovascular disease and hypoglycaemia in patients with type 2 diabetes: the Action in Diabetes and Vascular Disease: Preterax and Diamicron Modified Release Controlled Evaluation (ADVANCE) trial. Diabetologia. 2009 Nov;52(11):2328-36.

14. Tiwari SC, Tripathi RK, Farooqi SA, Kumar R, Srivastava G, Kumar A. Diabetes mellitus: A risk factor for cognitive impairment amongst urban older adults. Industrial psychiatry journal. 2012 Jan;21(1):44.

15. Cernea S, Zoltai C, Berbecilă D, Şular FL. Prevalence of Depression, Anxiety and Cognitive Impairment in Patients with Type 2 Diabetes from the Central Part of Romania. Acta Medica Marisiensis. 2016 Jun 1;62(2).

16. Alagiakrishnan K, Zhao N, Mereu L, Senior $\mathrm{P}$, Senthilselvan A. Montreal Cognitive Assessment (MOCA) Is Superior To Mmse In Detecting Mild Cognitive Impairment (MCI) In Middle Age And Elderly Type 2 Diabetes Mellitus.: C102. Journal of the American Geriatrics Society. 2013 Apr;61.

17. Ruis C, Biessels GJ, Gorter KJ, Van Den Donk M, Kappelle LJ, Rutten GE. Cognition in the early stage of type 2 diabetes. Diabetes care. 2009 Jul 1;32(7): 1261-5.

18. Cox DJ, Kovatchev BP, Gonder-Frederick LA, Summers KH, McCall A, Grimm KJ, Clarke WL. Relationships between hyperglycemia and cognitive performance among adults with type 1 and type 2 
Shivani D. Godhasara et.al. To assess the prevalence of cognitive impairment in type II diabetes mellitus: an observational study.

diabetes. Diabetes care. 2005 Jan 1;28(1): 71-7.

19. Biessels GJ, van der Heide LP, Kamal A, Bleys RL, Gispen WH. Ageing and diabetes: implications for brain function. European journal of pharmacology. 2002 Apr 19;441(1-2):1-4.

20. Kumar R, Looi JC, Raphael B. Type 2 diabetes mellitus, cognition and brain in aging: A brief review. Indian journal of psychiatry. 2009 Jan;51(Suppl1):S35.

21. Salthouse TA. When does age-related cognitive decline begin?. Neurobiology of aging. 2009 Apr 1;30(4):507-14.
22. Ferris S, Nordberg A, Soininen H, DarrehShori T, Lane R. Progression from Mild Cognitive Impairment to Alzheimer's disease: effects of gender, butyrylcholinesterase genotype and rivastigmine treatment. Pharmacogenetics and genomics. 2009 Aug;19(8):635.

How to cite this article: Godhasara SD, Suthar V. To assess the prevalence of cognitive impairment in type II diabetes mellitus: an observational study. Int J Health Sci Res. 2021; 11(11): 306-312. DOI: https://doi.org/10.52403 /ijhsr.20211136 